\title{
Non-Pharmacological Management of Hand Osteoarthritis: From A Perspective of Physiatry
}

\author{
Nihan Cuzdan Coskun ${ }^{1}$ and IIke Coskun Benlidayi ${ }^{2 *}$ \\ ${ }^{1}$ Faculty of Medicine, Department of Physical Medicine and Rehabilitation, Division of Rheumatology, Cukurova University, Adana, Turkey \\ ${ }^{2}$ Department of Physical Medicine and Rehabilitation, Cukurova University, Adana, Turkey
}

\begin{abstract}
Hand Osteoarthritis (OA) is a common disorder, particularly among female population aged 55 and above. It presents with pain and bony enlargements of the finger joints. Management of hand OA is based particularly on the non-pharmacological methods. These include joint protection education, use of splints in trapeziometacarpal joint $\mathrm{OA}$ and thermal agents for relief of pain and stiffness. In this article, a literature review was performed on the nonpharmacological management of hand $\mathrm{OA}$, as a means of updating the current knowledge and revealing the level of evidence regarding the non-pharmacological modalities used for hand OA. Meta-analysis, systematic reviews, reviews and randomized controlled trials were included, whereas single case reports and non-randomized studies were excluded. In non-pharmacological management of hand OA, current evidence supports the beneficial effects of joint protection education, exercise treatment, splinting and heat application, whilst evidence on electrotherapy, aquatherapy, balneotherapy remains low. Magnetotherapy, yoga and acupuncture still require further well-designed studies with high methodological quality.
\end{abstract}

Keywords: Hand osteoarthritis; Non-pharmacological management; Physical therapy; Rehabilitation

\section{Introduction}

Hand Osteoarthritis (OA) is a common OA phenotype, which particularly affects females. According to the results from Rotterdam study, radiographic hand OA is present in $67 \%$ of women and $54.8 \%$ of men at the age of 55 or above [1]. Although radiographic hand OA is almost universally present in elderly, symptomatic hand OA is less common, with a percentage of $8.2 \%$ and $15.9 \%$, in males and females, respectively $[2,3]$. On the other hand erosive hand OA was reported as, $2.8 \%, 5.0 \%$ and $10.2 \%$, in the general, radiographic and symptomatic hand OA population, respectively [4]

Patients with hand OA usually present with pain and enlargement of the finger joints, particularly in the dominant hand [5]. Hand pain was reported by $16 \%$ of the general population and $19 \%$ of the radiographic hand OA population. Besides, in patients with erosive hand OA, the percentage of pain was $40 \%$. Hand disability is another consequence of hand OA. In patients with radiographic hand OA, the hand disability rate is $2.3 \%$, whilst it is $7.3 \%$ in erosive OA patients [4]. Since it includes several disorders including thumb base hand OA, nodal interphalangeal $\mathrm{OA}$ and erosive $\mathrm{OA}$, the presentation of the disease varies among sufferers of hand OA. Nevertheless, the clinical hallmarks of hand OA are the bony enlargements of the joints, along with Heberden and Bouchard nodes [6].

Management of hand OA is a complex issue that includes the pharmacological, surgical and mainly, the non-pharmacological interventions [7]. Non-pharmacological modalities recommended for hand $\mathrm{OA}$ are instruction in joint protection techniques, use of splints in trapeziometacarpal (TMC) joint OA and thermal agents for relief of pain and stiffness [8]. Besides, exercise therapy is widely prescribed to patients with hand $\mathrm{OA}$, in order to improve joint range of motion, as well as muscle strength and tendon lengthening $[7,9]$.

Since the treatment of hand OA is based particularly on the nonpharmacological methods, herein, we aimed to review the current literature on the non-pharmacological management of hand OA, by means of using evidence based approach (Table 1). This review article was conducted at the department of Physical Medicine and Rehabilitation, Cukurova University Faculty of Medicine between June-September 2014. For this purpose, the MEDLINE database between 1975-2014 was searched by using the primary search terms or their synonyms, individually or in combination, including 'hand osteoarthritis', 'non-pharmacological management', 'physical modalities' and 'rehabilitation'. A total of 3733 articles were found. Single case reports, non-randomized studies without any control group were excluded $(\mathrm{n}=2915)$. Meta-analysis, systematic reviews, review articles and randomized controlled trials were included $(n=818)$. The titles and abstracts of the included articles were reviewed by two independent reviewers. Articles on surgical modalities, with nonspecified patient groups and/or non-specified modalities and/or nonvalidated outcomes and duplicates were excluded $(n=766)$.

\section{Joint Protection Education}

Joint protection education (JPE) is recommended by international guidelines, as the first line management of hand OA $[7,8,10]$. According to the systematic review of Valdes et al., there is moderate evidence to support JPE and provision of adaptive equipment for improvement in pain and hand function [11]

Joint Protection Education is instructed to patients either alone or together with exercise and splinting in randomized controlled trials

*Corresponding author: Ilke Coskun Benlidayi, Assistant Professor, Department of Physical Medicine and Rehabilitation, Faculty of Medicine, Cukurova University, Adana, Turkey, Tel: +90 53854539 37; Fax: +90 32233864 29; E-mail: icbenlidayi@hotmail.com

Received September 29, 2014; Accepted October 30, 2014; Published November 03, 2014

Citation: Coskun NC, Benlidayi IC (2014) Non-Pharmacological Management of Hand Osteoarthritis: From A Perspective of Physiatry. J Arthritis 3: 141. doi:10.4172/2167-7921.1000141

Copyright: (c) 2014 Coskun NC, et al. This is an open-access article distributed under the terms of the Creative Commons Attribution License, which permits unrestricted use, distribution, and reproduction in any medium, provided the original author and source are credited. 
Citation: Coskun NC, Benlidayi IC (2014) Non-Pharmacological Management of Hand Osteoarthritis: From A Perspective of Physiatry. J Arthritis 3: 141. doi:10.4172/2167-7921.1000141

Page 2 of 5

\begin{tabular}{|c|c|c|c|}
\hline Author & Intervention & Comparator & Results/Conclusion \\
\hline Stamm T et al. [12] & JPE + HE & Oral/written information about hand $\mathrm{OA}$ & $\mathrm{JPE}+\mathrm{HE}>$ information in improving HF and grip strength \\
\hline Boustedt C et al. [14] & Splints + HE + JPE & Informative sessions & $\begin{array}{l}\text { Splints }+\mathrm{HE}+\mathrm{JPE}>\text { information in decreasing pain, stiffness, disability } \\
\& \text { increasing grip strength }\end{array}$ \\
\hline Rogers MW et al. [15] & Strength exercises & Sham control (cross-over design) & Exercises >sham in decreasing pain and increasing grip strength \\
\hline Lefler $\mathrm{C}$ et al. [16] & Strength exercises & Routine activities & Strength exercises >routine activities in increasing grip strength \& ROM \\
\hline Moratz V et al. [13] & OT & None & Improvement in HF \\
\hline Dziedzic K et al. [30] & OT & JPE vs no JPE \& HE vs no HE & JPE vs no JPE and HE vs no HE had higher OARSI responders' rate \\
\hline Garfinkel MS et al. [20] & Yoga & Regular outpatient care & $\begin{array}{l}\text { Yoga >regular care in decreasing pain, joint tenderness and increasing } \\
\text { grip strength }\end{array}$ \\
\hline Fioravanti A et al. [23] & Spa therapy & Regular outpatient care & Spa>regular care in decreasing pain, morning stiffness and increasing HF \\
\hline Kovács C et al. [24] & Balneotherapy & $\begin{array}{l}\text { Balneotherapy with sulphurous thermal } \\
\text { water vs balneotherapy with warm tap water }\end{array}$ & $\begin{array}{l}\text { Balneotherapy with sulphurous thermal water >balneotherapy with tap } \\
\text { water in decreasing pain and improving HF, QoL after 3-6 months; no } \\
\text { difference was observed beyond } 6 \text { months }\end{array}$ \\
\hline Horváth $\mathrm{K}$ et al. [43] & $\begin{array}{l}\text { Balneotherapy } \\
\text { (with twodifferent } \\
\text { temperatures of } \\
\text { thermal water) }\end{array}$ & Magnetotherapy & $\begin{array}{l}\text { Balneotherapy >magnetotherapy in decreasing pain and improving HF } \\
38^{\circ} \mathrm{C} \text { thermal water improved pinch strength additionally }\end{array}$ \\
\hline Dickens W et al. [25] & Acupuncture & Sham control (mock TENS) & $\begin{array}{l}\text { Acupuncture >sham in decreasing pain, tenderness and increasing grip } \\
\text { strength, HF }\end{array}$ \\
\hline Field T et al. [26] & Massage & Regular outpatient care & $\begin{array}{l}\text { Massage>regular care in decreasing pain, depression mood scores } \\
\text { and increasing grip strength }\end{array}$ \\
\hline Stange-Rezende L et al. [33] & $\begin{array}{l}\text { Infrared radiation of } \\
\text { a tiled stove }\end{array}$ & Sham control (cross-over design) & Infrared radiation=routine care with no effect on pain \\
\hline Dilek B et al. [34] & Paraffin + JPE & Regular outpatient care + JPE & $\begin{array}{l}\text { Paraffin>regular outpatient care in improving pain, HF, grip and pinch } \\
\text { strengths }\end{array}$ \\
\hline Myrer JW et al. [35] & Paraffin & $\begin{array}{l}\text { Paraffin } \% 100 \text { wax (PT) vs paraffin } \% 80 \\
\text { wax and } \% 20 \text { topical analgesic (PTA) }\end{array}$ & PTA $>$ PT in decreasing pain and improving $\mathrm{HF}$ \\
\hline Renklitepe N et al. [37] & TENS & Glove electrode vs carbon electrode & $\begin{array}{l}\text { TENS with glove electrode>TENS with carbon electrode in decreasing } \\
\text { pain }\end{array}$ \\
\hline Brosseau L et al. [38] & LLLT & Sham control & LLLT = sham in decreasing pain and increasing HF \\
\hline Kanat E et al. [42] & Magnetotherapy & Sham control & Magnetotherapy > sham in decreasing pain and improving HF, QoL \\
\hline Gomes Carreira AC et al. [51] & Splinting & Regular outpatient care & $\begin{array}{l}\text { Splinting > routine care in decreasing pain and improving grip strength, } \\
\text { pinch strength and HF }\end{array}$ \\
\hline Rannou F et al. [50] & Splinting & Regular outpatient care & Splinting > routine care in decreasing pain and improving HF \\
\hline Swigart CR et al. [52] & Splinting & None (retrospective design) & Decrease in pain after splinting CMC joint for 3-4 weeks \\
\hline Buurke JH et al. [53] & Splinting & $\begin{array}{l}\text { Supple elastic splint vs elastic splint with } \\
\text { semi-rigid thumb vs semi-rigid splint }\end{array}$ & $\begin{array}{l}\text { No difference between groups regarding pain and supple elastic splints } \\
\text { were preferred for comfort and function and semi-rigid splints were } \\
\text { preferred for cosmetic concerns }\end{array}$ \\
\hline Weiss S et al. [54] & Splinting & $\begin{array}{l}\text { Short vs long splint vs no splint (cross-over } \\
\text { design) }\end{array}$ & $\begin{array}{l}\text { Short splint }>\text { long splint }>\text { no splint in increasing stabilization of } \mathrm{CMC} \text { in } \\
\text { both splints and no change in pain, grip strength between groups and } \\
\text { short splint was preferred by patients }\end{array}$ \\
\hline Weiss S et al. [55] & Splinting & $\begin{array}{l}\text { Custom-Made Thermoplastic splint (CMT) } \\
\text { vs Prefabricated Neoprene Splint (PFN) } \\
\text { (cross-over design) }\end{array}$ & $\begin{array}{l}\text { PFN splint >CMT splint in decreasing pain and improving function; } \\
\text { CMT splint >PFN splint in reducing subluxation at the first CMC joint; } \\
\text { PFN splint was preferred to the CMT splint by patients }\end{array}$ \\
\hline
\end{tabular}

JPE: Joint Protection Education; HE: Hand Exercise; OA: Osteoarthritis; HF: Hand Function;ROM: Range of Motion; OT: Occupational Therapy; OARSI: Osteoarthritis Research Society International; QoL: Quality of Life; TENS: Transcutaneous Electrical Nerve Stimulation; LLLT: Low Level Laser Therapy; CMC: Carpometacarpal

Table 1: Summary of the included clinical trials in the review.

(RCTs) [12-16] The two RCTs investigating the effect of JPE pointed that the intervention of JPE along with exercise could improve hand function, with the improvement in grip strength, without any change regarding pain $[12,13]$.

It should be noted that JPE instruction is not a time-consuming intervention, with several benefits and no expenses.

\section{Exercise Therapy}

As for many chronic conditions, exercise therapy also has several beneficial effects on OA $[17,18]$. In clinical practice, exercise therapy is generally included in physiotherapy programs, by physicians and physical therapists.

According to the European League against Rheumatism (EULAR) recommendations for the management of hand $\mathrm{OA}$, both range of motion (ROM) and strengthening exercise regimens are recommended in the treatment program [7]. However, due to the lack of direct evidence of benefit, the recommendation remains at the level of expert opinion. In the American College of Rheumatology (ACR) recommendations, exercise therapy is not included as a non-pharmacologic therapeutic option; since there is no strong evidence supporting its beneficial effect [8]. Osteoarthritis Research Society International (OARSI) 2009 recommendations report the pain relief effect of exercise for knee and hip OA; however, there was no comment on the effect of hand OA in this updated guideline [19].

There are four major purposes of exercise therapy for hand OA; decreasing stiffness, decreasing pain, improving ROM and increasing grip strength. In the RCTs, various combinations of therapeutic exercise programs are instructed to patients. Among these, ROM exercises together with strengthening exercises are the common prescribed 
exercise regimens for hand OA. According to a systematic review which included 21 articles of therapy-spesific interventions for hand $\mathrm{OA}$, strengthening exercises alone or in combination with ROM exercises are found to be effective in increasing grip strength and decreasing stiffness, with a weak to moderate evidence $[11,15,16,20]$. The only study which investigated the effectiveness of strengthening exercise therapy with a sham control group, showed modestly improved hand strength in the exercise group, while there was no change in the sham group [15]. In this study, exercise protocol including 9 exercises with 10 to 20 repetitions was given to hand OA patients daily for 16 weeks [15]. Pain is frequently used as an outcome measure in these studies because of its direct relation with hand function. Exercise intervention, particularly in combination with hand splints seems to relieve night and motion pain as shown in a study which the Carpometacarpal (CMC) splint was prescribed to patients together with ROM and strengthening exercise program [14]. However, the strength of evidence regarding the effectiveness of strengthening exercises alone, on pain, remains low.

Aquatic exercises and balneotherapy are popular therapeutic options in many painful musculoskeletal conditions [21]. According to the systematic review conducted by Kamioka et al., aquatic exercises are effective, as well as land exercises, in various joint involvements of $\mathrm{OA}$ in short term; while the evidence in balneotherapy remains unclear [22]. Currently, there is no study designed to investigate the effect of aquatic exercise in hand OA. Still, it is important to keep in mind that aquatic exercises are safe, cheap and easy to perform. Additionally, less strain on the joints and optional therapeutic thermal effect can be considered as the advantages of the therapy. Two recent studies on balneotherapy showed the beneficial overall effects of therapy on symptomatic hand OA in short term, especially in pain scores; albeit the long-term effectiveness was similar to controls in both studies $[23,24]$. Both studies have the intervention of thermal water bath with similar temperature $\left(37-38^{\circ} \mathrm{C}\right)$ for 15 to 20 minutes. However, the mineral ingredients of thermal water, intervals and the duration of the therapy were different.

The effectiveness of yoga is investigated in one study performed by Garfinkel et al. [20]. An exercise program with 60 minutes of supervised yoga and relaxation techniques was performed by patients once weekly for 8 times. According to the results of this study, that yoga therapy is effective in increasing grip strength, as well as decreasing pain and joint tenderness [20]. Similarly, acupuncture therapy is also beneficial in decreasing pain and disability, in accordance with a RCT by Dickens et al [25]. Despite high methodological quality and clearly described intervention ( 6 sessions, 2 week duration, TMC joint), the low number of patients reduces the validity of results [25]. Further research is needed to support these results, since these are the unique studies on yoga and acupuncture therapy, with low level of evidence.

Massage therapy was also found to be effective in hand OA patients with pain. Patients who received massage therapy by a therapist once a week for 4 weeks period, showed more improvement in depression and anxiety scores, when compared with controls. Although the study is in low quality, the ease of self-administration and the mood-improvement effect makes the therapy method considerable [26].

Occupational Therapy (OT) is consisted of JPE and exercise therapy for hand OA. Even though EULAR recommendations included OT for hand OA management, systematic reviews on this issue revealed that there is lack of evidence to reach a definitive conclusion [27-29]. One trial with 77 patients aimed to evaluate the effectiveness of OT in hand $\mathrm{OA}$, revealed the improvement in hand function, by means of an exercise regimen held by an occupational therapist (every two weeks for 12 weeks), in combination with JPE [13]. Likewise, the results of a recently published multicentre RCT support the superiority of JPE together with hand exercises given by occupational therapists, on written advice alone [30]. However, there is an urgent need for RCTs with high methodological quality to provide stronger evidence on this subject.

In conclusion, RCTs performed to investigate the effect of exercise therapy in hand OA are at low quality and the clinical outcome measures are not standardized [11,28,31]. In addition, different intensities and durations of exercise programs do not allow authors to obtain a consensus on an effective standardized exercise regimen.

\section{Physical Modalities}

\section{Heat and cold}

Applying heat is known to be a good therapeutic choice for many chronic conditions. However, in acute inflammation or edema, thermotherapy is not recommended as a therapeutic option [32]. Apart from aforementioned conditions, local heat applications can be used safely in OA.

According to EULAR recommendations, thermotherapyincluding local hot pack and ultrasound (US) therapy is proposed as an expert opinion in hand OA [7]. Also, ACR recommendations support the instruction of thermal modalities in the non-pharmacological management of hand OA [8].

There is limited number of RCTs evaluating the effectiveness of heat application, specifically for hand OA. Infrared radiation, which is a superficial heat modality, was used for hand OA, in a crossover study. Both groups received the infrared radiation of a tiled stove therapy 3 hours for 3 times a week during 3 weeks and treatment free periods alternately. After 6 weeks, the groups showed no difference in terms of pain and function scores [33].

One of the most commonly used heat modalities in the trials is paraffin $[14,34,35]$. Studies demonstrated relief of pain in short and long term, following the treatment with paraffin. The only singleblind controlled trial on this issue belongs to Dilek et al. [34]. The intervention group was treated for both hands, with 15 minutes of deep-wrap paraffin bath therapy $\left(50^{\circ} \mathrm{C}\right)$ for 5 days per week during 3 weeks. Accordingly, although no improvement was achieved in hand function, there was improvement both in pain and stiffness. Consequently, paraffin bath can be considered as a good local thermal therapeutic approach for symptomatic hand OA.

Diathermy is recommended in knee OA by international guidelines $[7,8]$. Nevertheless, to our knowledge, there is no trial concerning the effect of US, short wave diathermy or microwave diathermy, specifically on hand OA. Considering the effects of thermotherapy on pain relief and muscle relaxing, ultrasound therapy is worth to investigate in hand OA.

No controlled trials were encountered following our literature search regarding cold application for hand OA. Still, cold application is a frequently used method for acute inflammation of joints in rheumatic diseases [36]. Hence, cold application might be considered for acute exacerbations of inflammation in involved joints of hand OA.

\section{Electrotherapy}

There are a number of trials that investigated the role of electrotherapy on the treatment of hand OA $[37,38]$. Transcutaneous electrical nerve stimulation (TENS) with glove electrode is more 
effective than that with carbon electrode, in individuals with hand OA. Besides, low laser therapy was shown to be an effective method for increasing ROM, in hand OA. However, it has no effect on hand pain, function and stiffness according to a study where $3 \mathrm{~W} / \mathrm{cm}^{2}$ modulated mode Gallium Aluminium Arsenide (GaAlAs) was applied to finger joints and 3 superficial nerves for 3 weeks [38]. Magnetotherapy is an alternative physical therapy agent used for many diseases such as rheumatologic diseases, ischemic disorders in lower extremity and intracranial pathologies $[39,40]$. The magnetic induction is believed to cause a flow of ionic current through the cell, with a result of a healing effect, by the cytoprotection of cells and stimulation of growth factor synthesis [41]. Magneototherapy was found effective in improving pain and hand function by single-blind pilot trial of Dilek et al., in which the patients were allocated to exercise and exercise+magnetotherapy groups [42]. In the trial of Horváth et al., the effect of magnetotherapy together with balneotherapy versus magnetotherapy alone was investigated; and the results showed superiority of combination therapy in terms of pain reduction [43]. Accordingly, both trials have shown the effect of magnetotherapy on pain in different regimens. While the aforementioned study of Dilek et al. used pulse magnetotherapy at 25 $\mathrm{Hz}, 450$ pulse/s, 20 minutes a day for 10 days; in the study of Horváth et al. pulse magnetic field therapy was used at $60 \mathrm{~Hz}, 20 \mathrm{~J}$ of 15 minutes for 3 times weekly during 3 weeks.

Although there are limited trials on electrotherapy, TENS, low laser therapy and magnetotherapy are known to be reliable therapeutic agents, in painful conditions [44-47]. More trials should be carried out in order to reach a definite conclusion on their beneficial effect in patients with hand $\mathrm{OA}$.

\section{Orthoses}

According to the EULAR management strategies for hand OA, splints for thumb base OA and orthoses for angular deformities are recommended [7]. Systematic reviews show low to moderate evidence to support this proposal $[11,48]$. A meta-analysis investigating the design and effect of splints in hand OA, demonstrates the significant pain relief effect of splints, by short and long-term usage [49]. Longterm use of carpometacarpal and inter-phalangeal joint splints at night, establishes pain relief, improvement in hand function, hand strength and ROM, while the short-term night use of splints improves hand strength and function [50,51]. Besides, splinting of carpometacarpal joint continuously for 3-4 weeks, is shown to be well-tolerated by the patients in every stage of hand OA [52].

Although the materials can differ (elastic, elastic with semi-rigid thumb, semi-rigid material), the diversity in the orthotics' material, does not change the pain reduction effect [53]. Howbeit, depending on the two RCTs with high quality, EULAR recommendations support thumb base splint with an inclusion of wrist component, in order to increase the effect of stabilization $[7,54,55]$.

Taken as whole, assistive devices are claimed as the most effective self-management methods by patients with OA, splinting might be included in the non-pharmacological management of hand OA, as a core component [56].

Taking into account that no strong evidence stands for any of the therapy methods above, there is an urgent requirement for comparative studies including sham control groups. Besides, even though there are moderate evidence for exercise and splinting, information about the intensity, interval and duration of regimen is lacking. So, it might be the concern of researchers to build a common consensus for an optimum exercise regimen. Additionally, weak evidence regarding the beneficial effect of aquatherapy, balneotherapy and electrotherapy must be fortified.

\section{Conclusion}

In the present paper, up-to-date information about the nonpharmacological and non-surgical treatment modalities for hand OA was reviewed. Limited numbers of high quality RCTs on nonpharmacological treatment modalities restrict international guidelines from providing recommendations with strong evidence on this subject. According to our present knowledge based on literature, there is moderate to high evidence supporting JPE, exercise, local application of heat therapy and splinting in hand OA, whilst there is low evidence regarding balneotherapy, magnetotherapy, electrotherapy and acupuncture. Additionally, consensus on the optimum intensity and duration of exercise therapy regimen is lacking. Since the conservative therapy methods are commonly preferred in hand OA, further research with high methodological quality is mandatory, in order to achieve a consensus on this issue.

\section{References}

1. Dahaghin S, Bierma-Zeinstra SM, Ginai AZ, Pols HA, Hazes JM, et al. (2005) Prevalence and pattern of radiographic hand osteoarthritis and association with pain and disability (the Rotterdam study). Ann Rheum Dis 64: 682-687.

2. Nelson $\mathrm{AE}$, Jordon JM. Osteoarthritis epidemiology and classification. In Hochberg MC, Silman AJ, Smolen JS, Weinblatt ME, Weisman MH (Eds.) Rheumatology (5th Edn.), Mosby Elsevier, Philadelphia 1709-1716.

3. Haugen IK, Englund M, Aliabadi P, Niu J, Clancy M, et al. (2011) Prevalence incidence and progression of hand osteoarthritis in the general population: the Framingham Osteoarthritis Study. Ann Rheum Dis 70: 1581-1586.

4. Kwok WY, Kloppenburg M, Rosendaal FR, van Meurs JB, Hofman A, et al. (2011) Erosive hand osteoarthritis: its prevalence and clinical impact in the general population and symptomatic hand osteoarthritis. Ann Rheum Dis 70: 1238-1242.

5. Altman RD. Clinical features of osteoarthritis. In: Hochberg MC, Silman AJ, Smolen JS, Weinblatt ME, Weisman MH, eds. Rheumatology, (5th Edn.) Mosby Elsevier, Philadelphia, P: 1723-1730.

6. Gabay O, Gabay C (2013) Hand osteoarthritis: new insights. Joint Bone Spine 80: $130-134$.

7. Zhang W, Doherty M, Leeb BF, Alekseeva L, Arden NK, et al. (2007) EULAR evidence based recommendations for the management of hand osteoarthritis: report of a Task Force of the EULAR Standing Committee for International Clinical Studies Including Therapeutics (ESCISIT). Ann Rheum Dis 66: 377 388.

8. Hochberg MC, Altman RD, April KT, Benkhalti M, Guyatt G, et al. (2012) American College of Rheumatology 2012 recommendations for the use of nonpharmacologic and pharmacologic therapies in osteoarthritis of the hand, hip, and knee. Arthritis Care Res (Hoboken) 64: 465-474.

9. Rannou F, Poiraudeau S (2010) Non-pharmacological approaches for the treatment of osteoarthritis. Best Pract Res Clin Rheumatol 24: 93-106.

10. Manara M, Bortoluzzi A, Favero M, Prevete I, Sciré CA, et al. (2013) Italian Society for Rheumatology recommendations for the management of hand osteoarthritis. Reumatismo 65: 167-185.

11. Valdes K, Marik T (2010) A systematic review of conservative interventions for osteoarthritis of the hand. J Hand Ther 23: 334-350.

12. Stamm T, van der Giesen F, Thorstensson C, Steen E, Birrell F, et al. (2009) Patient perspective of hand osteoarthritis in relation to concepts covered by instruments measuring functioning: a qualitative European multicentre study. Ann Rheum Dis 68: 1453-1460.

13. Moratz V, Muncie HL Jr, Miranda-Walsh H (1986) Occupational therapy in the multidisciplinary assessment and management of osteoarthritis. Clin Ther 9 Suppl B: 24-29.

14. Boustedt C, Nordenskiöld U, Lundgren Nilsson A (2009) Effects of a handjoint protection programme with an addition of splinting and exercise: one year follow-up. Clin Rheumatol 28: 793-799. 
Citation: Coskun NC, Benlidayi IC (2014) Non-Pharmacological Management of Hand Osteoarthritis: From A Perspective of Physiatry. J Arthritis 3: 141. doi:10.4172/2167-7921.1000141

Page 5 of 5

15. Rogers MW, Wilder FV (2009) Exercise and hand osteoarthritis symptomatology: a controlled crossover trial. J Hand Ther 22: 10-17.

16. Lefler C, Armstrong WJ (2004) Exercise in the treatment of osteoarthritis in the hands of the elderly. Clin Kinesiol 58: 13-17.

17. Beckwée D, Vaes P, Cnudde M, Swinnen E, Bautmans I (2013) Osteoarthritis of the knee: why does exercise work? A qualitative study of the literature. Ageing Res Rev 12: 226-236.

18. Bennell KL, Hinman RS (2011) A review of the clinical evidence for exercise in osteoarthritis of the hip and knee. J Sci Med Sport 14: 4-9.

19. Zhang W, Nuki G, Muscowitz RW, Abramson S, Altman RD, Arden NK, et al. (2010) OARSI recommendations for the management of hip and knee osteoarthritis: Part III: changes in evidence following systematic cumulative update of research published through January 2009. Osteoarthritis Cartilage 18: $476-499$.

20. Garfinkel MS, Schumacher HR Jr, Husain A, Levy M, Reshetar RA (1994) Evaluation of a yoga based regimen for treatment of osteoarthritis of the hands. J Rheumatol 21: 2341-2343.

21. Hall J, Swinkels A, Briddon J, McCabe CS (2008) Does aquatic exercise relieve pain in adults with neurologic or musculoskeletal disease? A systematic review and meta-analysis of randomized controlled trials. Arch Phys Med Rehabil 89 873-883.

22. Kamioka H, Tsutani K, Okuizumi H, Mutoh Y, Ohta M, et al. (2010) Effectiveness of aquatic exercise and balneotherapy: a summary of systematic reviews based on randomized controlled trials of water immersion therapies. J Epidemiol 20: 2-12.

23. Fioravanti A, Tenti S, Giannitti C, Fortunati NA, Galeazzi M (2014) Short- and long-term effects of mud-bath treatment on hand osteoarthritis: a randomized clinical trial. Int J Biometeorol 58: 79-86.

24. Kovacs C, Pecze M, Tihanyi A, Kovacs L, Balogh S, et al. (2012) The effect of sulphurous water in patients with osteoarthritis of hand. Double-blind, randomized, controlled follow-up study. Clin Rheumatol 31: 1437-1442.

25. Dickens W, Lewitt GT (1989) A single-blind, controlled and randomized clinical trial to evaluate the effect of acupuncture in the treatment of trapeziometacarpal osteoarthritis. Complementary Medical Research 3: 5-8.

26. Field T, Diego M, Delgado J, Garcia D, Funk CG (2011) Hand pain is reduced by massage therapy. Complement Ther Clin Pract 17: 226-229.

27. Mejjad O, Maheu E (2000) Therapeutic trials in hand osteoarthritis: a critical review. Osteoarthritis Cartilage 8 Suppl A: S57-63.

28. Towheed TE (2005) Systematic review of therapies for osteoarthritis of the hand. Osteoarthritis Cartilage 13: 455-462.

29. Mahendira D, Towheed TE (2009) Systematic review of non-surgical therapies for osteoarthritis of the hand: an update. Osteoarthritis Cartilage 17: 1263-1268.

30. Dziedzic K, Nicholls E, Hill S, Hammond A, Handy J, et al. (2013) Selfmanagement approaches for osteoarthritis in the hand: a $2 \times 2$ factorial randomised trial. Ann Rheum Dis.

31. Moe RH, Kjeken I, Uhlig T, Hagen KB (2009) There is inadequate evidence to determine the effectiveness of nonpharmacological and nonsurgical interventions for hand osteoarthritis: an overview of high-quality systematic reviews. Phys Ther 89: 1363-1370.

32. Batavia M (2004) Contraindications for superficial heat and therapeutic ultrasound: do sources agree? Arch Phys Med Rehabil 85: 1006-1012.

33. Stange-Rezende L, Stamm TA, Schiffert T, Sahinbegovic E, Gaiger A, et al. (2006) Clinical study on the effect of infrared radiation of a tiled stove on patients with hand osteoarthritis. Scand J Rheumatol 35: 476-480.

34. Dilek B, Gozum M, Sahin E, Baydar M, Ergor G, et al. (2013) Efficacy of paraffin bath therapy in hand osteoarthritis: a single-blinded randomized controlled trial. Arch Phys Med Rehabil 94: 642-649.

35. Myrer JW, Johnson AW, Mitchell UH, Measom GJ, Fellingham GW (2011) Topical analgesic added to paraffin enhances paraffin bath treatment of individuals with hand osteoarthritis. Disabil Rehabil 33: 467-474.

36. Schmidt KL, Ott VR, Röcher G, Schaller H (1979) Heat, cold and inflammation. Z Rheumatol 38: 391-404.

37. Renklitepe N, Dogan N, Kayhan O, Ozaras N (1995) Effects of different
TENS electrode types in degenerative joint disease of the hands. Fizik Tedavi Rehabilitasyon Dergisi 19: 204-208

38. Brosseau L, Wells G, Marchand S, Gaboury I, Stokes B, et al. (2005) Randomized controlled trial on low level laser therapy (LLLT) in the treatment of osteoarthritis (OA) of the hand. Lasers Surg Med 36: 210-219.

39. Jerabek J (1994) Pulsed magnetotherapy in Czechoslovakia--a review. Rev Environ Health 10: 127-134.

40. Levy HD (1993) Magnetotherapy: new technology. Neurol Res 15: 142-143.

41. Bachl N, Ruoff G, Wessner B, Tschan H (2008) Electromagnetic interventions in musculoskeletal disorders. Clin Sports Med 27: 87-105, viii.

42. Kanat E, Alp A, Yurtkuran M (2013) Magnetotherapy in hand osteoarthritis: a pilot trial. Complement Ther Med 21: 603-608.

43. Horváth K, Kulisch Á, Németh A, Bender T (2012) Evaluation of the effect of balneotherapy in patients with osteoarthritis of the hands: a randomized controlled single-blind follow-up study. Clin Rehabil 26: 431-441.

44. Stein C, Eibel B, Sbruzzi G, Lago PD, Plentz RD (2013) Electrical stimulation and electromagnetic field use in patients with diabetic neuropathy: systematic review and meta-analysis. Braz J Phys Ther 17: 93-104.

45. Chang WD, Lee CL2, Lin HY3, Hsu YC4, Wang CJ5, et al. (2014) A Metaanalysis of Clinical Effects of Low-level Laser Therapy on Temporomandibular Joint Pain. J Phys Ther Sci 26: 1297-1300.

46. Bjordal JM, Lopes-Martins RA, Joensen J, Couppe C, Ljunggren AE, et al. (2008) A systematic review with procedural assessments and meta-analysis of low level laser therapy in lateral elbow tendinopathy (tennis elbow). BMC Musculoskelet Disord 9: 75

47. Markov MS (2007) Magnetic field therapy: a review. Electromagn Biol Med 26 $1-23$.

48. Ye L, Kalichman L, Spittle A, Dobson F, Bennell K (2011) Effects of rehabilitative interventions on pain, function and physical impairments in people with hand osteoarthritis: a systematic review. Arthritis Res Ther 13: R28.

49. Kjeken I, Grotle M, Hagen KB, Osterås N (2014) Development of an evidencebased exercise programme for people with hand osteoarthritis. Scand J Occup Ther

50. Rannou F, Dimet J, Boutron I, Baron G, Fayad F, et al. (2009) Splint for baseof-thumb osteoarthritis: a randomized trial. Ann Intern Med 150: 661-669.

51. Gomes Carreira AC, Jones A, Natour J (2010) Assessment of the effectiveness of a functional splint for osteoarthritis of the trapeziometacarpal joint on the dominant hand: a randomized controlled study. J Rehabil Med 42: 469-474.

52. Swigart CR, Eaton RG, Glickel SZ, Johnson C (1999) Splinting in the treatment of arthritis of the first carpometacarpal joint. J Hand Surg Am 24: 86-91.

53. Buurke JH, Grady JH, de Vries J, Baten CT (1999) Usability of thenar eminence orthoses: report of a comparative study. Clin Rehabil 13: 288-294.

54. Weiss S, LaStayo P, Mills A, Bramlet D (2000) Prospective analysis of splinting the first carpometacarpal joint: an objective, subjective, and radiographic assessment. J Hand Ther 13: 218-226.

55. Weiss S, Lastayo P, Mills A, Bramlet D (2004) Splinting the degenerative basa joint: custom-made or prefabricated neoprene? J Hand Ther 17: 401-406.

56. Veitiene D, Tamulaitiene M (2005) Comparison of self-management methods for osteoarthritis and rheumatoid arthritis. J Rehabil Med 37: 58-60. 